\title{
Photovoltaic system behaviour with different loads.
}

\author{
Campayo Martín, J.J. ${ }^{1}$, Ramos Hernanz, J.A. ${ }^{1}$, Zamora Belver, I. ${ }^{1}$ \\ Larrañaga Lesaka, J. ${ }^{2}$, Zulueta Guerrero, E. ${ }^{3}$, Motrico Gogeaskoetxea, J. ${ }^{1}$ \\ ${ }^{1}$ Department of Electrical Engineering \\ University of the Basque Country \\ e-mail: jj.campayo@ehu.es, josean.ramos@ehu.es, inmaculada.zamora@ehu.es, joseba.motrico@ehu.es \\ ${ }^{2}$ Department of Management and Production Engineering \\ ${ }^{3}$ Department of Systems Engineering and Automatic
}

\begin{abstract}
This paper presents the analysis of influence of different loads, when these loads are connected to a small photovoltaic system. By means of tests, the interactions between the photovoltaic system and the different loads is visualized and analyzed. To achieve this goal, a sequence of starts and stops is established that are repeated with all the loads. Different parameters and wave forms have been registered to analyse the influence on the power quality.

This process allows comparing the behaviour of each load in the electric network. In next future, the measured values will be used to contrast results obtained by means of simulations.
\end{abstract}

\section{Key words}

Photovoltaic system, power quality, harmonic, flicker.

\section{Introduction}

Photovoltaic energy, is becoming one important way for obtaining energy. It consists on the conversion of solar radiation into electric power. This conversion is carried out in solar cells and, an energy with an almost null environmental impact is obtained. The systems require low maintenance and are easily monitored for their vigilance. The installations can be located near of the evacuation or consumption points and reduce transport distances.

One of the problems of this type of energy is the abrupt changes that occur in generation, because this depends on the existing solar radiation and a cloud can reduce the generation instantly. In winter the radiation decreases, and at night the production is zero. Therefore it is difficult to plan the amount of energy to be produced.

The photovoltaic modules can be operated isolated o connected to the grid but in both cases, to convert the solar radiation into electric power, different instruments are required. This new installed equipment, particularly the inverters, can introduce disturbances. These disturbances affect to the power quality and is necessary keep them in appropriate values.

The objective of this paper is to present the obtained results when analyzing different power quality parameters in an isolated photovoltaic system.

\section{PV System Components.}

The components in a system connected to the grid are:

- Solar Panels: Is the essential component that changes light into electricity. The solar cells can be "Single crystal silicon" or "Polycrystalline silicon”. Polycrystalline silicon is cheaper than single crystal silicon but not as effective in energy conversion.

- Inverters: Is the component that transforms DC into AC. Has great influence on the power quality.

In a isolated system besides is necesary:

- Charge controller: Controls the energy flow to the battery and from the battery.

- Batteries. In solar energy systems a lead-acid deep cycle battery is used. This type of battery is designed to be more tolerant with the cycles of charging and discharging.

\section{Tests.}

To analize the influence of photovoltaic systems in the power quality supply, different parametrers are considered. Some of them are the following:

- Disturbances in amplitude: voltage dip, supply transient interruption, overvoltage, transient events, voltage fluctuations, flicker...

- Disturbances of the frequency.

- Disturbances in the wave form, harmonics

- Disturbances in the symmetry: voltage or current unbalances.

Besides the photovoltaic system components, (panels, batteries, regulator and inverter), different loads have been used in the developed tests. These loads are:

- 2 energy saving lamps.

- $\quad$ Set of 50 leds.

- $\quad$ Set of 8 fluorescents lamps.

- 1 small single-phase electrical motor.

- 1 low pressure sodium vapour lamp.

- 1 high pressure mercury lamp. 
On the other hand, the power quality portable analyzer of Fluke 435 (CLASS A) is used as measurement equipment to register the different events. For the results analysis, the software "Power Log" of Fluke is used.

The figure 1 shows the system used to perform the test.

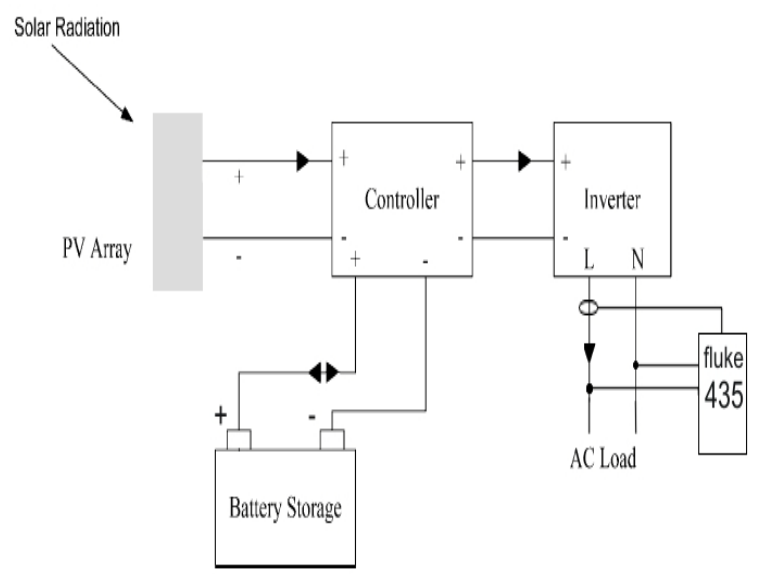

Fig. 1. Isolated system.

To analyse the behaviour of the photovoltaic system, different tests are performed. In these tests, the different loads are connected to the photovoltaic system and normal operation is emulated with starts and stops. A working protocol has been established. This protocol sets out the operating times and the starting and stopping (both hot and cold), for each load.

For the first four loads, the protocol times are the same. It starts with a cold-start up and the load stays connected for a minute until temperature is reached. The load turns off and then reconnects 30 seconds later, to make a hot start-up. After one minute a fault is simulated, and the inverter is turns off for 30 seconds. Finally the inverter with the load is connected for another 30 seconds.

The latest tests with discharge lamps have been done. The discharge lamps need a longer start-up time, and thus the sequence has been changed.

Moreover, the recording instrument is placed at the inverter output and is configured to capture the same parameters in all the tests.

\section{Results.}

\section{A. Energy saving lamps}

At the inverter output (figure 1), 2 energy saving lamps (25 watts) and the portable analyzer are connected. The switching sequence takes $31 / 2$ minutes as follow:

1. The load is connected one minute.

2. The load is disconnected for 30 seconds.

3. The energy saving lamps are connects for 1 minute again.

4. The inverter is disconnected 30 seconds.

5. Inverter and load are connected 30 seconds.

In figure 2 the graph of the voltage and current obtained by the measuring instrument can be seen.
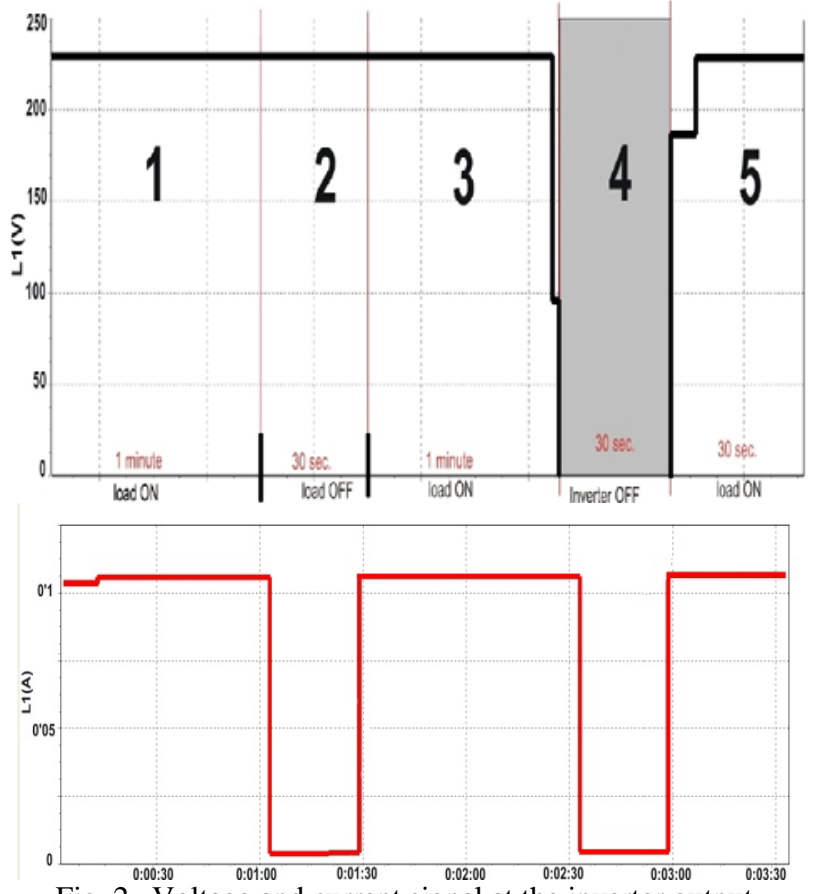

Fig. 2. Voltage and current signal at the inverter output.

The event recorder has captured 3 events: 1 voltage dip and two interruptions in this time interval (Fig. 3). But all of them related with the supply interruption when the inverter is disconnected. When the load is disconnected, signal the power quality is unaffected. A low power charge does not affect the signal of the inverter.

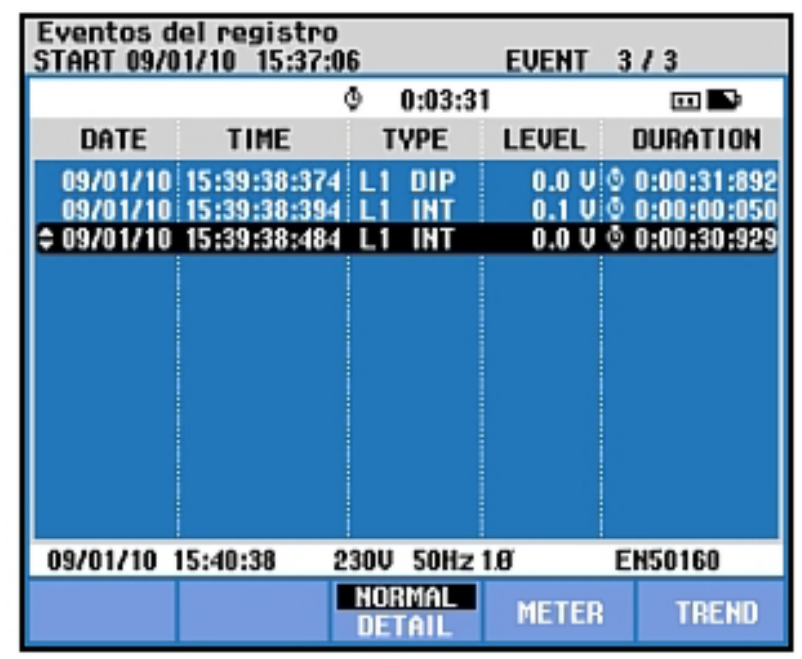

Fig. 3. Events of register.

It can be appreciated that the deformation in the waveform is high. The level of harmonics and the THD for voltage and current is showed in figure 4.

The THDi is produced by load. Although it is a very high value, the current magnitude is very small, and problems such as the risk of heating in the conductors are zero. THDv is produced by generator as a result of the distortion of the current. 


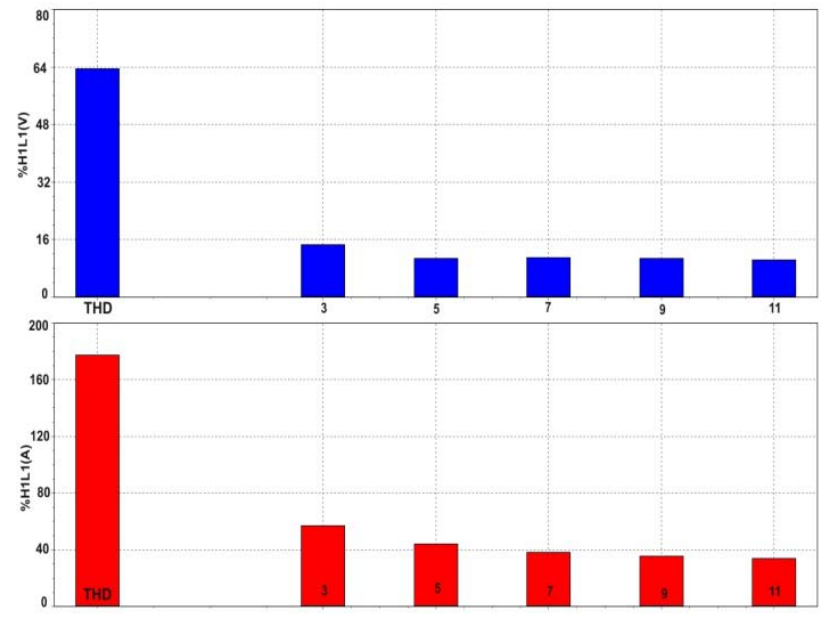

Fig. 4. THD and harmonics (V and I).

\section{B. Set of 50 leds.}

At the inverter output 50 LEDs (55 watts), and the Fluke 435 are conected (figure 1). The switching secuence is the same as for energy-saving lamps (section 4.A).

The results obtained are equivalent to those obtained with low energy lamps. The event recorder has captured 3 events during the supply interruption, 2 voltage dip and 1 interruption when the inverter is disconnected.

The THD values are lower than in the previus section but still high, as shown in Figure 5.

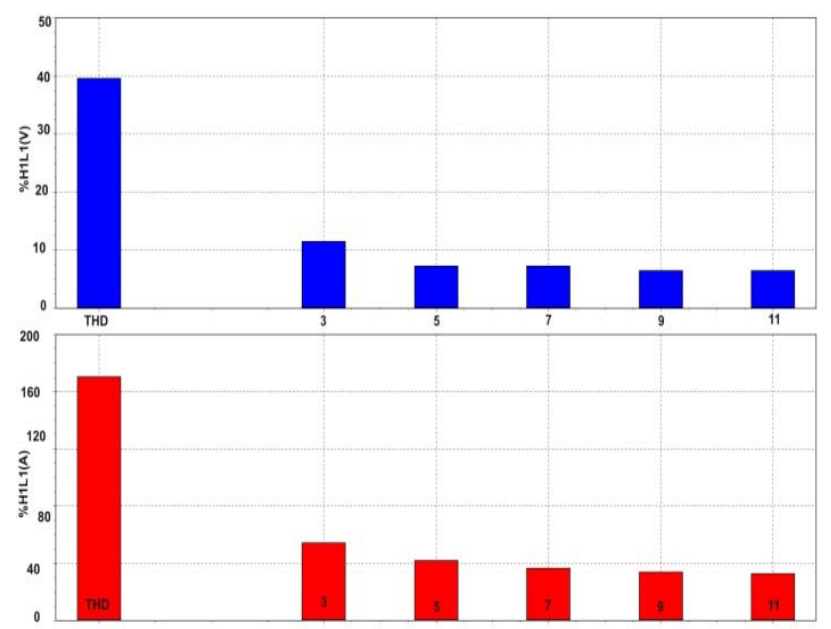

Fig. 5. THD and harmonics (V and I).

Since power and current magnitudes are very low, the importance of these values is limited since the generator and the conductors will support these values without problems.

\section{Set of 8 fluorescents lamps.}

At the inverter output 8 fluorescents lamps (144 watts) and the Fluke 435 are connected (figure 1). The switching sequence is $3 \frac{1}{2}$ minutes as in the previous cases.

The event recorder has captured 7 events: 5 voltage dips ( $\mathrm{t}<100 \mathrm{~ms}$.), 1 over voltage when the lamps are turned off and one interruption (with the inverter switched off).
THD values are in an acceptable range, below $10 \%$. Figure 6 shows a time evolution of the harmonics. During normal operation of the system, the values are low. However, during the disconnection of the inverter, this electronic device generates higher values.

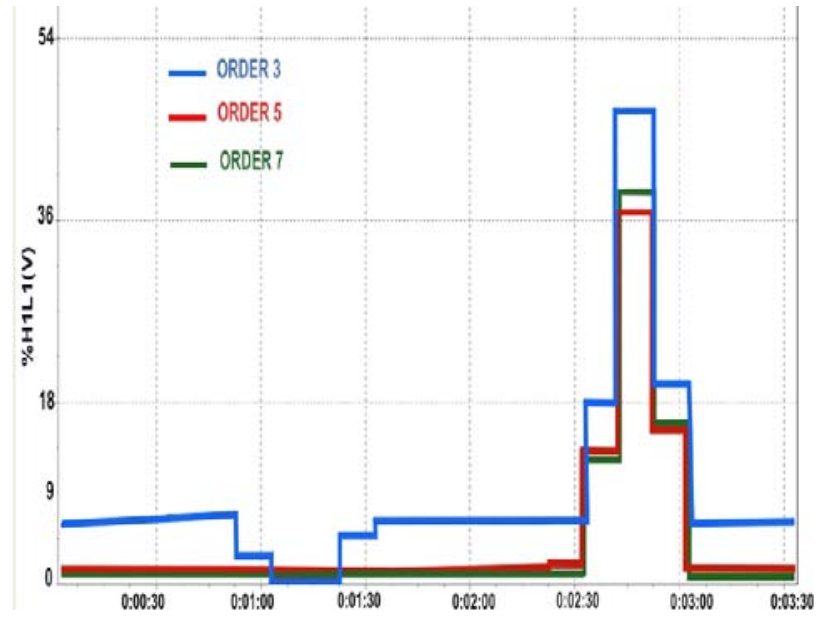

Fig.6. Temporal evolution of harmonics.

In this same interval, the recorder has captured eight transients as the result of the switching of the inverter. All of them have occurred when the inverter is starting after the interruption. The transients have an important effect on some types of load. They can produce deprogramming (PLC's...) or erratic behaviour caused by the interferences over a data bus for example but in this test the fluorescents lamps are not affected by transients. Figure 7 shows the first of the 8 captured.

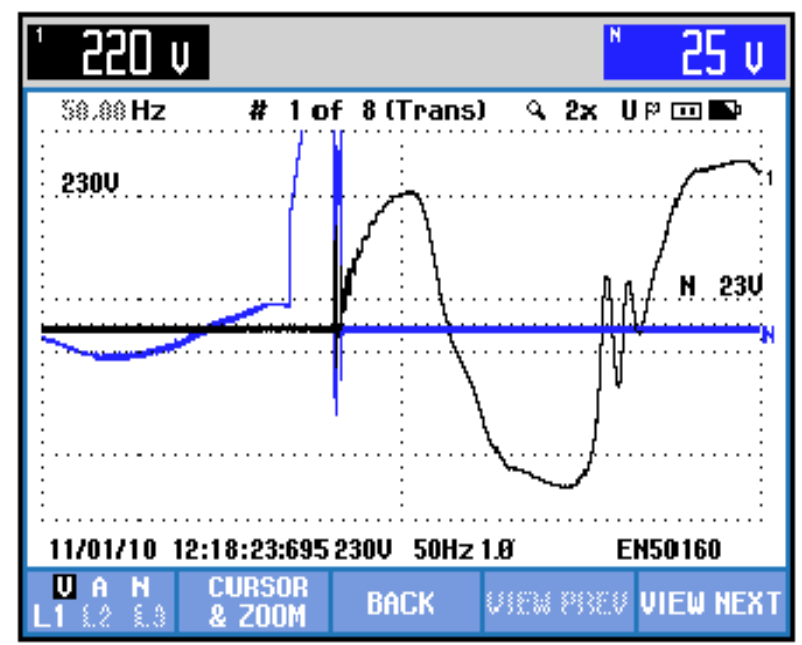

Fig.7. Captured transient.

\section{Small single-phase electrical motor.}

At the inverter output a small single-phase electrical motor (120 watts) and the Fluke 435 are connected (figure 1 ). The switching sequence is $31 / 2$ minutes as in the previous cases.

During the first minute of operation, the motor is rotating in vacuum. In the second minute the motor is working with charge. In figure 8 current and voltage evolution for this time interval can be seen. 

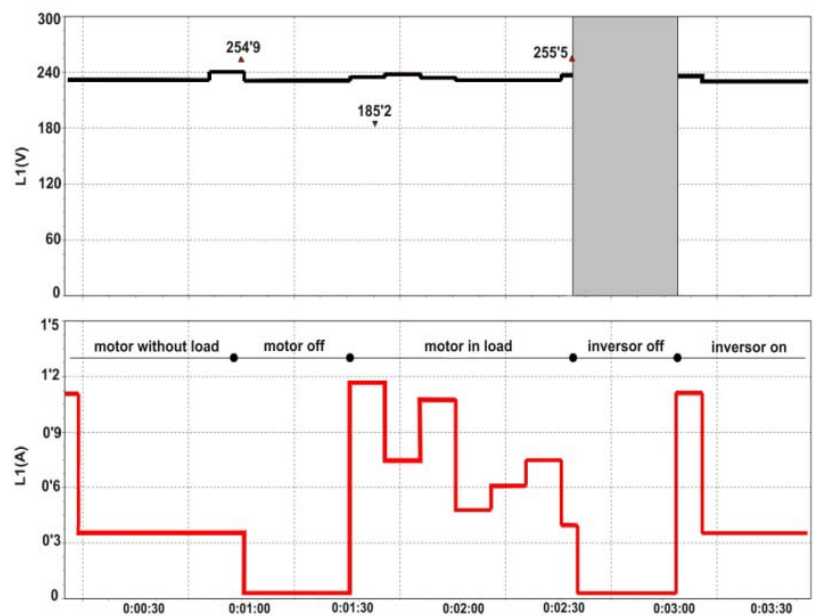

Fig.8. Voltage and current signal at the inverter output.

During the second interval of operation, the electrical motor has been forced by a non-constant load, (as seen in figure 8). Also, there is a voltage dip $\left(185^{\prime} 2 \mathrm{~V}\right)$ with a duration of $130 \mathrm{~ms}$, as can be seen in figure 9. Probably it is due to an overload on the electrical motor. Its rated current takes a value of 0'6A and in that moment consumption is 1'2 A, (Fig. 8).

\begin{tabular}{|c|c|c|c|c|c|}
\hline Fecha & Función & Duración & LL1 Min & L1 Med & L1 Max \\
\hline $11 / 01 / 2010122.29 .45663 \mathrm{~ms}$ & THDV & \multirow{7}{*}{ On. 0s. $130 \mathrm{~ms}}$. & \multirow{4}{*}{$\begin{array}{l}1,68 \% \\
167.11 \% \\
1,29 \%\end{array}$} & $1,72 \%$ & \multirow{4}{*}{$\begin{array}{l}1,77 \% \\
189,96 \% \\
64,26 \%\end{array}$} \\
\hline $11 / 01 / 201012: 29.45663 \mathrm{~ms}$ & THDA & & & $179,24 \%$ & \\
\hline $11 / 01 / 201012229.45663 \mathrm{~ms}$ & THDW & & & $5,1 \%$ & \\
\hline $11 / 01 / 201012: 29.45663 \mathrm{~ms}$ & Pit & & & 0 & \\
\hline $11 / 01 / 201012: 29.45663 \mathrm{~ms}$ & $P_{s t}$ & & & 0 & \\
\hline $11 / 01 / 201012229.52959 \mathrm{~ms}$ & Hueco & & $185,2 \mathrm{~V}$ & & \\
\hline $11 / 01 / 201012: 29.55663 \mathrm{~ms}$ & Tensión & & $209.29 \mathrm{~V}$ & $229,46 \mathrm{~V}$ & $233,94 \mathrm{~V}$ \\
\hline $11 / 01 / 201012: 29.55663 \mathrm{~ms}$ & Corriente & & $0,024 \mathrm{~A}$ & $0,572 \mathrm{~A}$ & $1,168 \mathrm{~A}$ \\
\hline $11 / 01 / 201012229.55663 \mathrm{~ms}$ & Peak Vollage & & $303.5 \mathrm{~V}$ & $333,4 \mathrm{~V}$ & $341,8 \mathrm{~V}$ \\
\hline $11 / 01 / 201012: 29.55663 \mathrm{~ms}$ & Peak Current & & $0,03 A$ & $0,446 \mathrm{~A}$ & $1.594 \mathrm{~A}$ \\
\hline $11 / 01 / 201012: 29.55663 \mathrm{~ms}$ & V Factor de Cresta & & 1,35 & 1,45 & 1.63 \\
\hline $11 / 01 / 201012229.55663 \mathrm{~ms}$ & A Factor de Cresta & & 1,36 & 327,67 & 327,67 \\
\hline $11 / 01 / 201012: 29.55663 \mathrm{~ms}$ & Hall Cycle Vollage & & $185,17 \mathrm{~V}$ & $229,44 \mathrm{~V}$ & $237.99 \mathrm{~V}$ \\
\hline $11 / 01 / 2010122.29 .55663 \mathrm{~ms}$ & Half Cycle Current & & $0,022 \mathrm{~A}$ & $0,572 \mathrm{~A}$ & $1,171 \mathrm{~A}$ \\
\hline $11 / 01 / 2010122.29 .55663 \mathrm{~ms}$ & Potencia Activa & & ow & $65,333 \mathrm{~W}$ & $256,667 \mathrm{~W}$ \\
\hline $11 / 01 / 201012: 29.55663 \mathrm{~ms}$ & Potencia Aparente & & $5,333 \mathrm{VA}$ & $73,333 \mathrm{VA}$ & $268 \mathrm{VA}$ \\
\hline $11 / 01 / 201012: 29.55663 \mathrm{~ms}$ & Potencia Reactiva & & 6VAR & 24VAR & 116VAR \\
\hline $11 / 01 / 201012.29 .55663 \mathrm{~ms}$ & Factor de Potencia & & .0 .01 & 0.27 & 0.98 \\
\hline
\end{tabular}

Besides 2 over-voltages have been detected (figure 10). This situation is due to the fact that the motor (inductive load) causes a over-voltage at the time of disconnection.

\begin{tabular}{|c|c|c|c|c|c|}
\hline Fecha & Función & Duración & L1 Min & L1 Med & L1Max \\
\hline 11/01/201012:29:05 663ms & THDV & \multirow{11}{*}{ Om. 0s. 40ms. } & $1,27 \%$ & $1,28 \%$ & $1,3 \%$ \\
\hline 11/01/201012:29:05 663ms & THDA & & $4,33 \%$ & $4,39 \%$ & $4,46 \%$ \\
\hline 11/01/201012:29:05 663ms & THDW & & $0,02 \%$ & $0,03 \%$ & $0,03 \%$ \\
\hline 11/01/201012:29:05 663ms & Plt & & & 0 & \\
\hline 11/01/201012:29:05 663ms & Pst & & & 0 & \\
\hline 11/01/201012:29:14910ms & Pico & & & & $254,9 \mathrm{~V}$ \\
\hline $11 / 01 / 201012: 29: 15663 \mathrm{~ms}$ & Tensión & & $227 \mathrm{~V}$ & $229,98 \mathrm{~V}$ & $239,23 \mathrm{~V}$ \\
\hline 11/01/201012:29:15663ms & Corriente & & $0,024 \mathrm{~A}$ & $0,335 \mathrm{~A}$ & $0,358 \mathrm{~A}$ \\
\hline $11 / 01 / 201012: 29: 15663 \mathrm{~ms}$ & Peak Vollage & & $326,4 \mathrm{~V}$ & $329,5 \mathrm{~V}$ & $366,4 \mathrm{~V}$ \\
\hline 11/01/201012:29:15663ms & Peak Current & & $0,03 \mathrm{~A}$ & $0,512 \mathrm{~A}$ & $0,566 \mathrm{~A}$ \\
\hline 11/01/201012:29:15663ms & V Factor de Cresta & & 1,42 & 1,43 & 1,53 \\
\hline
\end{tabular}

Fig.10. registered values.

The values of harmonics, as shown in figure 11, can be considered within the correct margins.
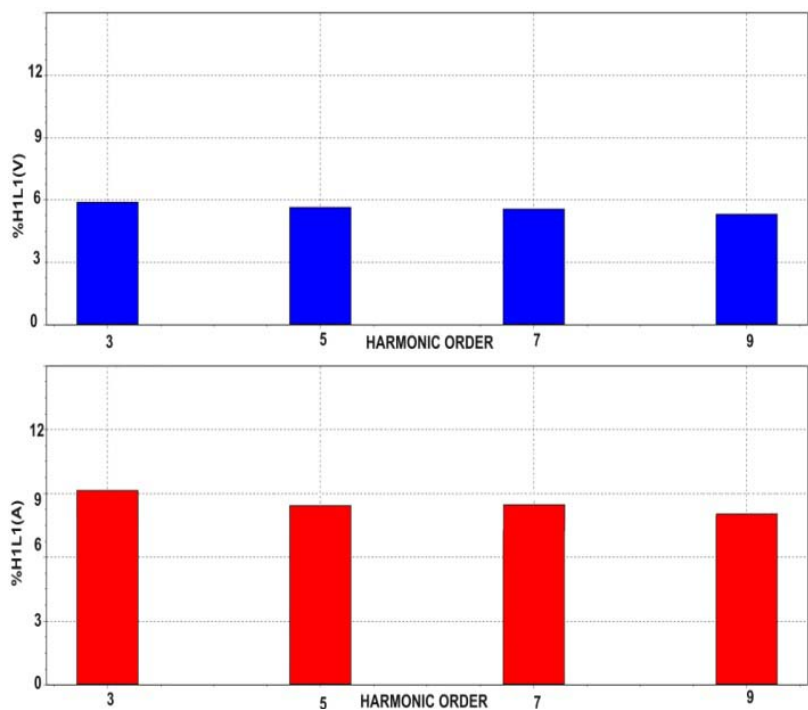

Fig. 11. Values of harmonics (V and I).

\section{E. Low pressure sodium vapor lamp.}

At the inverter output, a low pressure sodium vapour lamp (55 watt) with his ballast and the Fluke 435 are connected (figure1).

The total starting time of a discharge lamp is longer that other lamps, therefore the working protocol has been changed:

1. The load is connected and stays until it stabilizes, about 12 minutes.

2. The inverter is disconnected for one minute.

3. It connected again and is maintained until stabilization, about 2 minutes.

In figure 12 , voltage and current evolution for the last minutes of test can be seen.
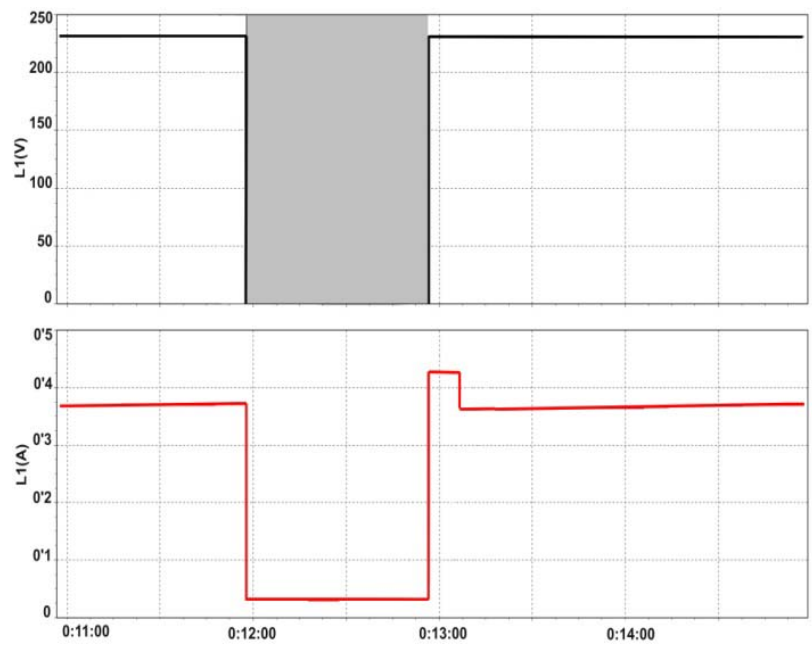

Fig.12. Voltage and current signal at the inverter output.

After disconnecting one minute, the inverter is reconnected and the lamp starts up normally. However, a small interval of time is needed to regain the previous state. The register does not detect any interruption.

The inverter has generated five transients during reconnection, such as that shown in figure 13. 


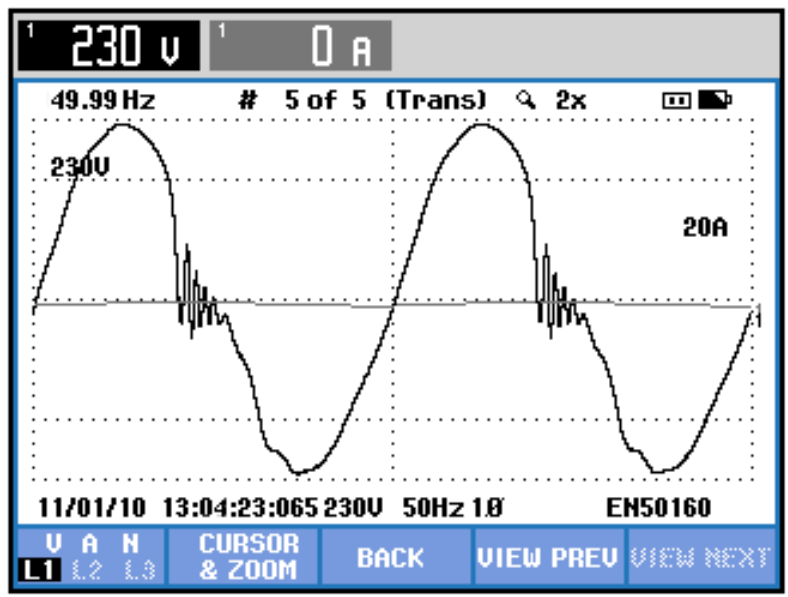

Fig.13. Captured transient.

\section{F. Low pressure sodium vapor lamp and the discharged battery.}

When batteries are discharged, the inverter tries to keep the load only with the energy produced in the PV array. If the energy generated is not enough, the inverter makes a connection attempt per second. In figure 14 can see as after about 30 seconds, the energy generated by the sun is enough, and the normal operation of the load is restored.

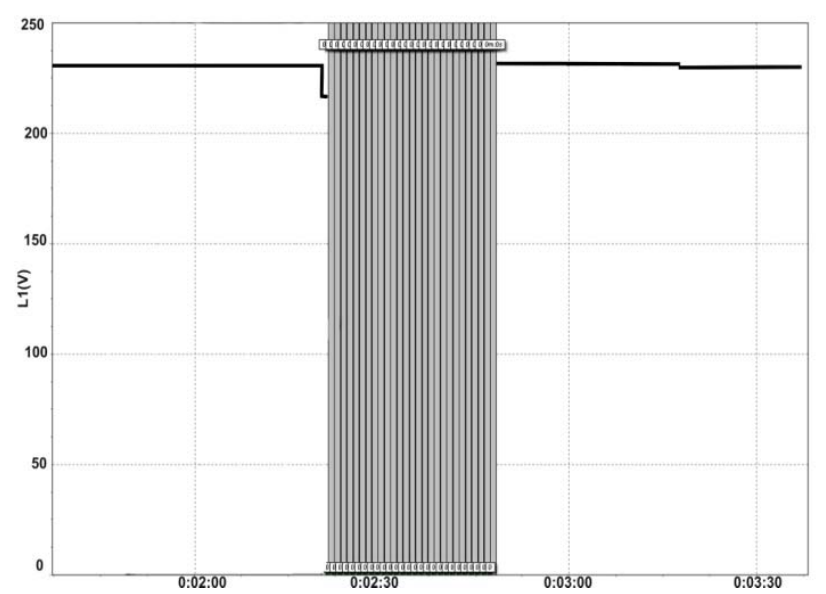

Fig.14. Voltage signal at the inverter output.

During this period, 29 voltage dips and 21 transients were identified.

In this situation, the inverter injects disturbances to the grid. These disturbances should be corrected if for example, there are sensitive loads connected or the system is connected to the grid.

\section{G. High pressure mercury lamp.}

At the inverter output, a high pressure mercury lamp (125 watt) with his ballast and the portable analyzer are connected (figure 1).

As with the low pressure sodium vapour lamp, the working protocol has been changed:

1. The load is connected and stays until it stabilizes, about 4 minutes.

2. The inverter is disconnected for 30 seconds.

3. The inverter is connected again, but the lamp needs more time to reconnect. It is necessary to wait for the mercury to condense. When this happens, the arc is striking again and the lamp starts as can be seen in figure 15 .

4. Is maintained until stabilization, about 2 minutes.

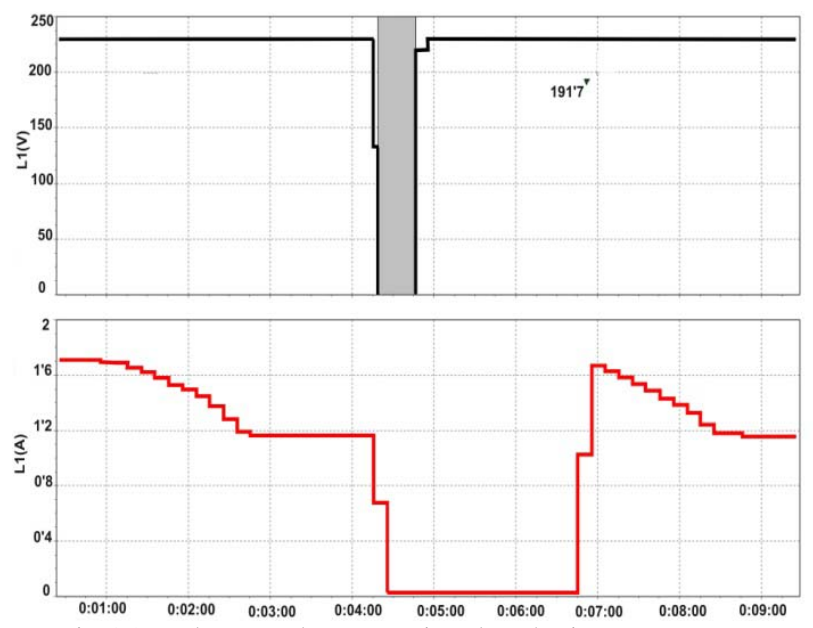

Fig.15. Voltage and current signal at the inverter output.

In this test, we must mention that only a voltage dip is generated at the time of reconnection, and as shown in figure 16 the harmonic level is good. The harmonic of order 3 is the most significant but all are within the correct margins.

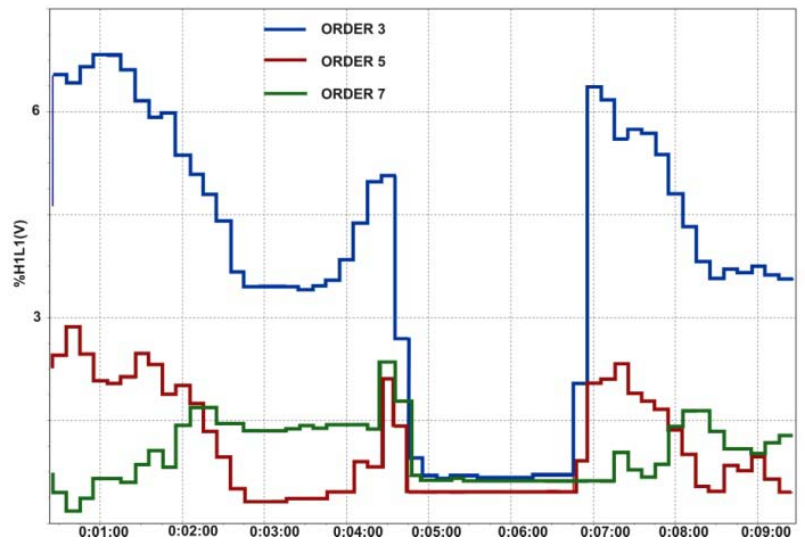

Fig.16. Temporal evolution of harmonics.

During reconnection, 6 transients as shown in figure 17 have been captured.

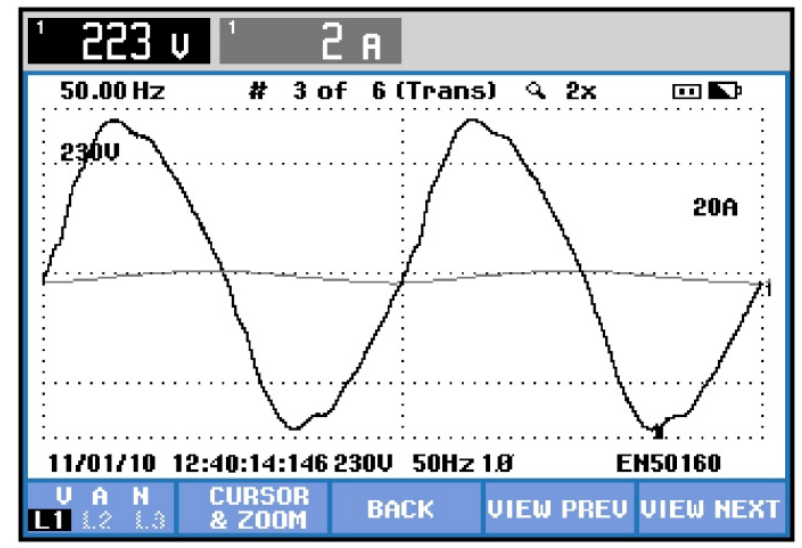

Fig.17. Captured transient.

With this type of load, the disturbances are less and with magnitude smaller that with other loads. 


\section{Conclusion}

The system tested is a low power system. The loads were chosen in function of this system, but represent loads typically used. In summary, we conclude:

- With all different types of loads major disturbances occur.

- These perturbations are always associated to commutations of the load. Sometimes is the connection or disconnection of the load, sometimes it's the start of the inverter, but always important voltage dips occur.

- In some cases, the total harmonic distortion (THD) is too high.

- As is an isolated system has no significance in the grid. If has been connected, would be necessary to correct this situation.

- As is a low-power system, the inverter is a weak generator and is very sensitive to the type of load that feeds.

- It remains for later analysis test with a more powerful system and connected to the grid.

\section{References}

[1] G. Chicco, J. Schlabbach, F. Spertino. "Experimental assessment of the waveform distortion in grid-connected photovoltaic installations". Solar Energy 83 (2009) 1026 1039

[2] M.A. Eltawil, Z, Zhao. "Grid-connected photovoltaic power systems: Technical and potential problems-A review". Renew Sustain Energy Rev (2009), doi:10.1016/j.rser.2009.07.015

[3] W. Negrão, R. Zilles. "Influence of the power contribution of a grid-connected photovoltaic system and its operational particularities". Energy for Sustainable Development 13 (2009) 202-211

[4] J.H.R. Enslin, P.J.M. Heskes. "Harmonic Interaction Between a Large Number of Distributed Power Inverters and the Distribution Network". IEEE TRANSACTIONS ON POWER ELECTRONICS, VOL. 19, NO. 6, NOVEMBER 2004

[5] P. Sanchis, J. López, A. Ursúa, E. Gubía, L, Marroyo. "On the Testing, Characterization, and Evaluation of PV Inverters and Dynamic MPPT Performance Under Real Varying Operating Conditions". PROGRESS IN PHOTOVOLTAICS: RESEARCH AND APPLICATIONS. Prog. Photovolt. Res. Appl. 2007; 15:541-556

[6] A. A. Pérez Miguel. N. Bravo de Medina, M. Llorente Antón, "La amenaza de los armónicos y sus soluciones", Editorial Paraninfo. Thomson Learning. ISBN: 84-2832737-8.

[7] J. Aristizabal, J. Hernández, G. Gordillo, “Analisis de calidad de potencia para un sistema fotovoltaico interconectado", SICEL 2003.

[8] Fluke, "Power Log. PC Application Software" Users Manual

[9] Standar EN 50160; Voltage characteristics of electricity supplied by public distribution systems. CENELEC, distributed in Spain by AENOR 